\title{
Article \\ Optimization by Means of Chemometric Tools of an Ultrasound-Assisted Method for the Extraction of Betacyanins from Red Dragon Fruit (Hylocereus polyrhizus)
}

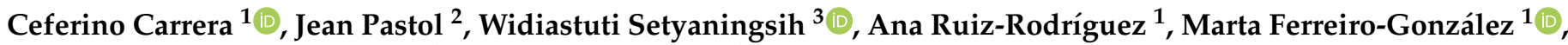 \\ Gerardo Fernández Barbero ${ }^{1, *(1)}$ and Miguel Palma ${ }^{1}$ (1) \\ 1 Department of Analytical Chemistry, Faculty of Sciences, Agrifood Campus of International \\ Excellence (ceiA3), University of Cadiz, IVAGRO, Puerto Real, 11510 Cadiz, Spain; \\ ceferino.carrera@uca.es (C.C.); ana.ruiz@uca.es (A.R.-R.); marta.ferreiro@uca.es (M.F.-G.); \\ miguel.palma@uca.es (M.P.) \\ 2 Department of Physical Measurements, Institute of Technology of Lannion, CEDEX, 22302 Lannion, France; \\ jeanpastol@gmail.com \\ 3 Department of Food and Agricultural Product Technology, Faculty of Agricultural Technology, \\ Gadjah Mada University, Jalan Flora, Bulaksumur, Sleman, Yogyakarta 55281, Indonesia; \\ widiastuti.setyaningsih@ugm.ac.id \\ * Correspondence: gerardo.fernandez@uca.es; Tel.: +34-956-01-6355
}

Citation: Carrera, C.; Pastol, J.; Setyaningsih, W.; Ruiz-Rodríguez, A.; Ferreiro-González, M.; Fernández Barbero, G.; Palma, M. Optimization by Means of Chemometric Tools of an Ultrasound-Assisted Method for the Extraction of Betacyanins from Red Dragon Fruit (Hylocereus polyrhizus) Agronomy 2021, 11, 1053. https:// doi.org/10.3390/agronomy11061053

Academic Editors: Mirosława Chwil and Renata Matraszek-Gawron

Received: 31 March 2021

Accepted: 17 May 2021

Published: 24 May 2021

Publisher's Note: MDPI stays neutral with regard to jurisdictional claims in published maps and institutional affiliations.

Copyright: (c) 2021 by the authors. Licensee MDPI, Basel, Switzerland. This article is an open access article distributed under the terms and conditions of the Creative Commons Attribution (CC BY) license (https:// creativecommons.org/licenses/by/ $4.0 /)$.

\begin{abstract}
Betacyanins have been reported to provide prominent health-promoting effects, in addition to contributing to the exotic color and pleasant palate of red dragon fruit that has been attracting universal interest for over a decade. An accurate determination of betacyanins in dragon fruit is important if we are to benefit from the nutraceutical features of these compounds. Seven betacyanin pigments have been identified and extracted by means of ultrasound-assisted techniques from red dragon fruit. Chemometric tools such as Box-Behnken Design (BBD) in conjunction with response surface methodology (RSM) have been successfully used to evaluate and optimize the relevant extraction variables i.e., temperature (A: $10,35,60^{\circ} \mathrm{C}$ ), solvent composition (B: 20, 50, 80\% methanol in water), sample to solvent ratio (C: 0.1:10, 0.2:10, 0.3:10 g/mL), power (D: 20, 45, 70\%), and cycle (E: $0.3,0.5,0.7 \mathrm{~s}^{-1}$ ). The results obtained from the analysis of variance (ANOVA) suggest that the solvent composition ( $p$ 0.0063), sample to solvent ratio ( $p$ 0.0126), and cycle ( $p$ 0.0302) are the most influential variables in betacyanin extraction. The optimal variable settings for ultrasound-assisted extraction (UAE) were a $54.6^{\circ} \mathrm{C}$ extraction temperature, $0.3 \mathrm{~s}^{-1}$ cycle, $20 \%$ ultrasound power, $21.4 \%$ methanol in water solvent composition, 0.2:10 sample to solvent ratio, and a 5 min extraction time. The validation of the method for repeatability and intermediate precision provided excellent results at $1.56 \%$ and $2.94 \%$ respectively. Furthermore, the novel UAE method was successfully used for the determination of betacyanins content in red dragon fruit from different geographic origins.
\end{abstract}

Keywords: Box-Behnken; liquid chromatography; purple pitaya; response surface methodology; ultrasound-assisted extraction; UHPLC

\section{Introduction}

Red dragon (Hylocereus polyrhizus (F.A.C.Weber) Britton \& Rose) is one of the varieties of sweet dragon or pitaya whose fruits have red flesh and red skin. A set of pigments, viz. betacyanins, are responsible for the typical red color of this fruit and have been demonstrated to exhibit considerable antioxidant activity with potential applications in functional foods [1] Betacyanins have been reported to provide a number of prominent functional properties such as nephroprotective [2], antioxidant [3], anti-inflammatory [4], and osteoarthritis pain relief [5]. Because of these health-promoting effects, in addition to its exotic red color and pleasing palate, red dragon fruit has attracted global interest over the last decade. Hence, the 
determination of betacyanin content in dragon fruit is important if we intend to benefit from its nutraceutical properties in the form of functional foods.

The development of reliable methods for the extraction of these compounds with such powerful antioxidant capacities presents a number of challenges, since betacyanins interact rapidly with other compounds present in the matrix that lead to their degradation. According to a previous study on betacyanin stability these compounds are resistant to heating $\left(100{ }^{\circ} \mathrm{C}\right)$ and a 3.7 to $5.5 \mathrm{pH}$ medium for just $10 \mathrm{~min}$ [6]. These shortcomings presented by traditional extraction technologies, together with their large energy consumption, the usage of large amounts of solvent as well as their long processing times have encouraged analytical chemists to search for novel "green" extraction techniques that require lower power consumption, less solvent and shorter extraction times. Consequently, some novel extraction techniques have been considered as potential methods that would use smaller amounts of solvent combined with high-power systems to achieve a rapid extraction of the antioxidants. Some of such methods would be pressurized liquid extraction (PLE) $[7,8]$, ultrasound-assisted extraction (UAE) $[9,10]$ and microwave-assisted extraction (MAE) [11,12]. Of all these methods, UAE seems to be the most practical one, since it is more economical and is compatible with a wide variety of extraction solvents [13].

UAE has been previously employed for the extraction of betacyanins from colored quinoa [14], red beet [15], and red prickly pear, both peels and pulps [16]. The cavitation effect caused by ultrasounds represents an advantage when extracting certain compounds from solid matrices. UAE's efficiency is also determined by the ultrasounds' cycle and frequency, the solvent composition and the operating temperature. Naturally, these extraction variables should be evaluated and optimized in order to achieve a full recovery of the analytes of interest.

Therefore, this research study has focused on the optimization of the UAE extraction method based on two combined chemometric tools: Box-Behnken Design (BBD) and response surface methodology (RSM). These chemometric tools have allowed us to successfully evaluate and optimize the known factors that are more likely to affect the UAE extraction processes' efficiency level $[17,18]$. Naturally, the subsequently developed method was validated and applied to determining betacyanin contents in real red dragon fruit samples.

\section{Materials and Methods}

\subsection{Chemicals and Reagents}

The extraction solvent contained water and methanol. A Milli-Q water purification system from Millipore (Bedford, MA, USA) supplied the ultra-pure water for the solvent. The HPLC-grade methanol was purchased from MercK (Darmstadt, Germany). HPLC-grade formic acid was supplied by Scharlau S.L. (Sentmenat, Barcelona, Spain). For the study of the antioxidant activity, DPPH (2,2-diphenyl-1-picrylhydrazyl) radical scavenging was obtained from Sigma-Aldrich (San Luis, MI, USA) and 6-hydroxy-2,5,7,8tetramethylchroman-2-carboxylic acid (Trolox) (Sigma-Aldrich, Steinheim, Germany) was used as the standard control.

\subsection{Red Dragon Fruit Samples}

Fresh red dragon fruit from three different geographical origins was purchased from producers at each origin, Jakarta (Indonesia), Chipiona (Spain) and Veracruz (Mexico). Before the extraction, the fruit samples were lyophilized by means of a VirTis BenchTop Pro Freeze Dryer (SP Industries, Warminster, PA, USA) and ground using an electric MKM6003 coffee grinder (BSH Electrodomésticos España S.A., Zaragoza, Spain). The ground samples were stored at $-20{ }^{\circ} \mathrm{C}$ prior to their analysis. The three different samples were mixed and homogenized to be used in the experimental design. The optimized and validated extraction method was applied to analyze the red dragon fruit samples from each one of the three geographical origins. 


\subsection{Ultrasound-Assisted Extraction (UAE)}

The equipment used for the UAE extractions was a UP200S ultrasonic device (Hielscher Ultrasonics $\mathrm{GmbH}$, Teltow, Germany) with a diameter probe of $7 \mathrm{~mm}$. The ultrasound waves were applied at 200 watts and $24 \mathrm{kHz}$. The temperature of the UAE process was controlled by means of a Frigiterm J.P. water bath purchased from Selecta, Abrera, Spain, that can operate in the range of $-10^{\circ} \mathrm{C}$ to $100{ }^{\circ} \mathrm{C}$. The red dragon fruit powder was accurately weighed following the experimental design and then was poured into the extraction vessel together with $25 \mathrm{~mL}$ solvent (at different concentrations of methanol in water depending on the corresponding experiment of the design: $20-50-80 \%$ ). Once the extraction had been completed, the supernatant was separated from the solid material by means of a centrifuge (J.P. Selecta, Abrera, Spain) running at $8000 \mathrm{rpm}\left(9.5 \mathrm{~cm}\right.$ orbital radius) for $5 \mathrm{~min}$ at $4{ }^{\circ} \mathrm{C}$. The precipitate was afterwards rinsed using fresh solvent and the resulting liquid was combined with the supernatant to be adjusted to the volume established by the experiment design (DOE). The extract was filtered through a nylon syringe filter $(0.22 \mu \mathrm{m})$ prior to its injection into a UHPLC-diode array detector (DAD) system.

\subsection{Betacyanins Determination}

The separation and quantification of the betacyanins in the UAE extracts were conducted by means of a Chromaster UltraRS (VWR Hitachi, Tokyo, Japan) fitted with a 6430 diode array detector. The equipment consisted in a 6270 autosampler, a 6310 column oven, and 6170 binary pump. The column was a Fused-Core C18 (Phenomenex Kinetex, CoreShell Technology, Torrance, CA, USA; $100 \times 2.1 \mathrm{~mm}$ I.D., particle size $2.6 \mu \mathrm{m}$ ) and the oven was set at $50{ }^{\circ} \mathrm{C}$. The mobile phase was a binary solvent consisting in phase A ( $5 \%$ formic acid in water) and phase $\mathrm{B}$ (methanol) at a flow rate of $1.0 \mathrm{~mL} \mathrm{~min}{ }^{-1}$. The 10 min programmed gradient was as follows (time, \% solvent B): $0 \mathrm{~min}, 15 \% ; 1.50 \mathrm{~min}, 20 \%$; $3.30 \mathrm{~min}, 30 \%$; $4.80 \mathrm{~min}, 40 \%$; $5.50 \mathrm{~min}, 55 \%$; $5.90 \mathrm{~min}, 60 \%$; $6.60 \mathrm{~min}, 95 \%$; $9.30 \mathrm{~min}, 95 \%$; $10 \mathrm{~min}, 100 \%$. The extracts were filtered through a $0.2 \mu \mathrm{m}$ nylon syringe filter (Membrane Solutions, Dallas, TX, USA) prior to chromatographic analysis. The injection volume was set at $3 \mu \mathrm{L}$. All the analyses were carried out in duplicate. Figure 1 shows the chromatogram $(\lambda=538 \mathrm{~nm})$ indicating the seven betacyanin compounds that were identified.

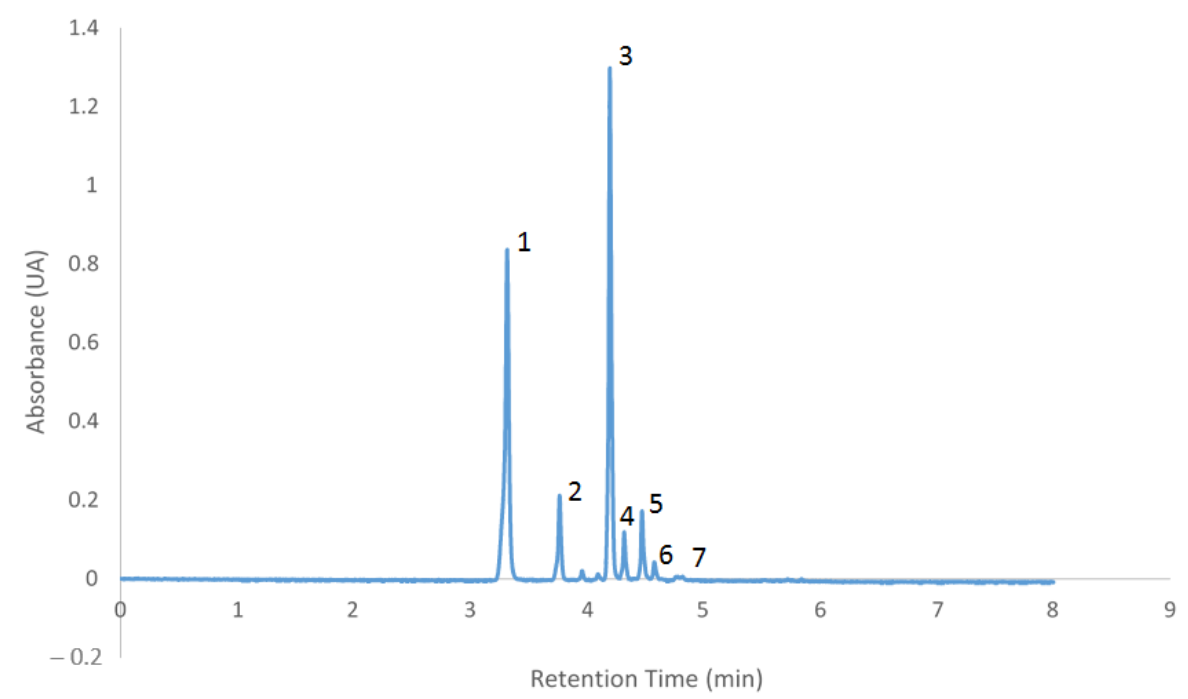

Figure 1. Chromatogram of the betacyanins detected in the red dragon fruit extract samples $(\lambda=538 \mathrm{~nm})$.

The total betacyanins was determined by colorimetric analysis. The red dragon fruit extract was diluted with deionized water to obtain absorption values in the adequate range. The absorbance was measured at $538 \mathrm{~nm}$ using a Cary $60 \mathrm{UV}$-Vis spectrophotometer 
(Agilent Technologies, Santa Clara, CA, USA). The total betacyanin content was calculated according to Equation (1):

$$
\text { Betacyanin content }(\mathrm{mg} / \mathrm{g})=\frac{A \times V \times D F \times M W \times 10^{-3}}{\varepsilon \times L \times W}
$$

where $A$ is the absorbance at $538 \mathrm{~nm}, V$ is the volume of extracts (L), DF is the dilution factor, $M W$ is the molecular weight of betanin $\left(550 \mathrm{~g} \mathrm{~mol}^{-1}\right), \varepsilon$ is the molar extinction coefficient of betanin $\left(65,000 \mathrm{~L} \mathrm{~mol}^{-1} \mathrm{~cm}^{-1}\right), L$ is the path length of the cuvette $(1 \mathrm{~cm})$, and $W$ is the weight of the sample.

\subsection{Identification of Betacyanins by UHPLC-QToF-MS}

The betacyanins present in the red dragon fruit samples were identified by ultraperformance liquid chromatography coupled to a quadrupole-time-of-flight mass spectrometer, (UHPLC-QToF-MS) (Xevo G2, Waters Corp., Milford, MA, USA). The analytical column used was a reverse-phase C18 (Acquity UPLC BEH C18, Waters) of $100 \times 2.1 \mathrm{~mm}$ and a particle size of $1.7 \mu \mathrm{m}$. Two mobile phases were used, $0.2 \%(v / v)$ formic acid in water solution as phase A and $0.2 \%(v / v)$ formic acid in acetonitrile solution as phase B. The UAE extracts were filtered through a $0.22 \mu \mathrm{m}$ nylon syringe filter (Membrane Solutions, Dallas, TX, USA). The flow rate was $0.55 \mathrm{~mL} / \mathrm{min}$ and the volume injected was $3 \mu \mathrm{L}$. The total programmed gradient was as follows (time, $\%$ solvent B): $0.00 \mathrm{~min}, 0 \% ; 1.00 \mathrm{~min}, 0 \% ; 3.00 \mathrm{~min}$, $5 \%$; $4.00 \mathrm{~min}, 10 \%$; $4.50 \mathrm{~min}, 10 \%$; $5.00 \mathrm{~min}, 20 \%$; $7.00 \mathrm{~min}, 20 \%$; $9.00 \mathrm{~min}, 100 \%$. The total run time was $13 \mathrm{~min}$, including $3 \mathrm{~min}$ for re-equilibration. The mass spectra were acquired in positive ion mode under the following conditions: desolvation gas flow $=700 \mathrm{~L} \mathrm{~h}^{-1}$, desolvation temperature $=500{ }^{\circ} \mathrm{C}$, cone gas flow $=10 \mathrm{~L} \mathrm{~h}^{-1}$, source temperature $=150^{\circ} \mathrm{C}$, capillary voltage $=700 \mathrm{~V}$, cone voltage $=30 \mathrm{~V}$, and collision energy $=20 \mathrm{eV}$. "Full Scan" mode was used $(m / z=100-1200)$. The individual betacyanins were identified based on their retention time and exact molecular weight.

\subsection{Antioxidant Activity}

In this work, the antioxidant activity of the extracts obtained from the three red dragon fruits varieties extracted under the optimal conditions was evaluated using the DPPH assays. For this assay, a $6 \times 10^{-5} \mathrm{M}$ DPPH solution was first prepared in methanol. Then, for each $100 \mu \mathrm{L}$ of red dragon fruit extract, $2 \mathrm{~mL}$ of the DPPH solution was added to the mixture. The mixture was incubated for $40 \mathrm{~min}$ in the absence of light and at room temperature. Then the absorbance was measured at $515 \mathrm{~nm}$. The linear regression for the trolox standards was constructed using 6 points $(0-1.4 \mathrm{mM})$ in triplicate. The regression equation $(y=88.94 \mathrm{x}+0.75)$ and the determination coefficient $\left(\mathrm{R}^{2}=0.9959\right)$ were calculated using Microsoft Office Excel 2013. The results were expressed as mg of trolox equivalents (TE) per $\mathrm{g}$ of dry weight sample ( $\left.\mathrm{mg} \mathrm{TE}^{-1} \mathrm{DW}\right)$. The antioxidant activity has been measured in triplicate.

\subsection{Experimental Design}

The Box-Behnken design (BBD) was used to evaluate the effects of the extraction variables on the recovery of the betacyanins. Five independent factors including temperature (A), solvent composition (B), sample to solvent ratio (C), power (D), and cycle (E), each one considered at 3 levels, were studied. Table 1 includes the design levels of the independent factors. The full BBD comprised 46 extractions that were performed randomly (Table 2). The data resulting from the chromatographic analyses of the extracts were used to develop a mathematical model where the response was to fit a second order polynomial function (Equation (2)) as shown below.

$$
\mathrm{y}=\beta_{0}+\sum_{i=1}^{k} \beta_{i} x_{i}+\sum_{i=1}^{k} \beta_{i i} x_{i}{ }^{2}+\sum_{i=1}^{k-1} \sum_{j=2}^{k} \beta_{i j x_{i} x_{j}}+\varepsilon
$$


where $x_{1}, x_{2}, \ldots, x_{k}$ are the UAE factors that influence the extraction efficiency, $y ; \beta_{0}, \beta_{i i}$ $(i=1,2, \ldots, k), \beta_{i j}(i=1,2, \ldots, k ; j=1,2, \ldots, k)$ are unknown parameters; $\varepsilon$ is a random error. The least square method was used to estimate the $\beta$ coefficients, whilst only secondorder interactions were considered.

Table 1. Range of values of the independent factors.

\begin{tabular}{ccccc}
\hline Factors & $\mathbf{- 1}$ & $\mathbf{0}$ & $\mathbf{+ 1}$ & Unit \\
\hline Temperature (A) & 10 & 35 & 60 & ${ }^{\circ} \mathrm{C}$ \\
Solvent composition (B) & 20 & 50 & 80 & $\%$ methanol in water \\
Sample to solvent ratio (C) & $0.1: 10$ & $0.2: 10$ & $0.3: 10$ & $\mathrm{~g} \mathrm{~mL}^{-1}$ \\
Ultrasound power (D) & 20 & 45 & 70 & $\%$ \\
Cycle (E) & 0.3 & 0.5 & 0.7 & $\mathrm{~s}^{-1}$ \\
\hline
\end{tabular}

Table 2. Box-Behnken design for the five independent variables with their observed responses.

\begin{tabular}{|c|c|c|c|c|c|c|}
\hline \multirow{2}{*}{$\begin{array}{l}\text { Experimental } \\
\text { Run }\end{array}$} & \multicolumn{5}{|c|}{ UAE Variables } & \multirow{2}{*}{$\begin{array}{c}\text { Relative Value with Respec } \\
\text { to the Maximum (\%) }\end{array}$} \\
\hline & $\mathbf{A}$ & B & $\mathrm{C}$ & D & $E$ & \\
\hline 1 & -1 & -1 & 0 & 0 & 0 & 67.53 \\
\hline 2 & -1 & 0 & +1 & 0 & 0 & 62.13 \\
\hline 3 & +1 & 0 & 0 & +1 & 0 & 65.47 \\
\hline 4 & 0 & 0 & +1 & -1 & 0 & 100.00 \\
\hline 5 & -1 & +1 & 0 & 0 & 0 & 73.59 \\
\hline 6 & +1 & +1 & 0 & 0 & 0 & 60.88 \\
\hline 7 & 0 & 0 & 0 & -1 & -1 & 86.77 \\
\hline 8 & 0 & 0 & 0 & 0 & 0 & 82.83 \\
\hline 9 & +1 & 0 & +1 & 0 & 0 & 89.11 \\
\hline 10 & 0 & 0 & +1 & 0 & +1 & 84.78 \\
\hline 11 & -1 & 0 & 0 & 0 & +1 & 92.11 \\
\hline 12 & +1 & 0 & -1 & 0 & 0 & 67.99 \\
\hline 13 & +1 & 0 & 0 & 0 & +1 & 74.27 \\
\hline 14 & 0 & 0 & -1 & +1 & 0 & 80.12 \\
\hline 15 & -1 & 0 & -1 & 0 & 0 & 76.71 \\
\hline 16 & 0 & 0 & 0 & 0 & 0 & 93.65 \\
\hline 17 & 0 & -1 & 0 & -1 & 0 & 91.10 \\
\hline 18 & 0 & 0 & 0 & 0 & 0 & 90.68 \\
\hline 19 & 0 & +1 & 0 & +1 & 0 & 67.31 \\
\hline 20 & 0 & 0 & -1 & 0 & +1 & 66.43 \\
\hline 21 & 0 & 0 & 0 & -1 & +1 & 87.87 \\
\hline 22 & 0 & +1 & 0 & 0 & +1 & 74.44 \\
\hline 23 & 0 & -1 & 0 & 0 & +1 & 65.49 \\
\hline 24 & 0 & 0 & +1 & +1 & 0 & 84.01 \\
\hline 25 & 0 & 0 & 0 & 0 & 0 & 81.30 \\
\hline 26 & 0 & 0 & 0 & +1 & +1 & 82.55 \\
\hline 27 & 0 & 0 & +1 & 0 & -1 & 87.14 \\
\hline 28 & 0 & 0 & -1 & 0 & -1 & 84.32 \\
\hline 29 & +1 & 0 & 0 & -1 & 0 & 83.03 \\
\hline 30 & 0 & 0 & 0 & 0 & 0 & 92.18 \\
\hline 31 & 0 & +1 & -1 & 0 & 0 & 48.39 \\
\hline 32 & -1 & 0 & 0 & +1 & 0 & 94.29 \\
\hline 33 & 0 & -1 & +1 & 0 & 0 & 85.51 \\
\hline 34 & 0 & +1 & 0 & -1 & 0 & 70.22 \\
\hline
\end{tabular}


Table 2. Conts.

\begin{tabular}{ccccccc}
\hline $\begin{array}{c}\text { Experimental } \\
\text { Run }\end{array}$ & A & B & C & D & E & $\begin{array}{c}\text { Relative Value with Respect } \\
\text { to the Maximum (\%) }\end{array}$ \\
\cline { 2 - 6 } 35 & 0 & +1 & 0 & 0 & -1 & 68.17 \\
36 & +1 & -1 & 0 & 0 & 0 & 69.55 \\
37 & 0 & -1 & -1 & 0 & 0 & 77.87 \\
38 & 0 & -1 & 0 & 0 & -1 & 96.42 \\
39 & 0 & 0 & -1 & -1 & 0 & 87.84 \\
40 & -1 & 0 & 0 & -1 & 0 & 62.38 \\
41 & 0 & 0 & 0 & 0 & 0 & 90.62 \\
42 & +1 & 0 & 0 & 0 & -1 & 83.18 \\
43 & 0 & +1 & +1 & 0 & 0 & 75.50 \\
44 & 0 & -1 & 0 & +1 & 0 & 78.27 \\
45 & 0 & 0 & 0 & +1 & -1 & 89.00 \\
46 & -1 & 0 & 0 & 0 & -1 & 94.84 \\
\hline
\end{tabular}

Temperature (A), solvent composition (B), sample to solvent ratio (C), power (D), and cycle (E).

\subsection{Statistical Analysis}

RSM equipment provided by STATGRAPHICS Centurion XVI (Statpoint Technologies, Inc., The Plains, VA, USA) was employed to optimize the UAE process in order to obtain the greatest possible recovery. Gnumeric 1.12 .17 was used to analyze the experimental data generated from single factor experiments. Analysis of variance (ANOVA, $p=0.05$ ) was used to determine the significance of the differences between the means. In the event that ANOVA suggested a significant difference, a least significant difference (LSD, $p=0.05$ ) test was used to verify the differences between the means.

\section{Results and Discussion}

\subsection{Identification of the Betacyanins}

Seven different betacyanins can be seen in the chromatogram of red dragon fruit extract (Figure 1). UHPLC-QToF-MS identification data are presented in Table 3. The identifications were based on molecular ion $[\mathrm{M}+\mathrm{H}]^{+}$and were in agreement with other identifications in previous studies $[19,20]$. Phyllocactin followed by betanin were the most abundant betacyanins in the samples.

Table 3. Betacyanins identified by UHPLC-QToF-MS.

\begin{tabular}{|c|c|c|c|c|c|c|}
\hline \multirow{2}{*}{$\mathbf{N}^{\circ}$} & \multirow{2}{*}{$\begin{array}{l}\text { Retention } \\
\text { Time (min) }\end{array}$} & \multicolumn{3}{|c|}{ MS (Positive Ion Mode) } & \multirow{2}{*}{$\begin{array}{l}\text { Molecular } \\
\text { Formula }\end{array}$} & \multirow{2}{*}{ Identification } \\
\hline & & Ion & Observed & Calculated & & \\
\hline 1 & 4.36 & {$[\mathrm{M}+\mathrm{H}]^{+}$} & 551.1512 & 551.1513 & $\mathrm{C}_{24} \mathrm{H}_{26} \mathrm{~N}_{2} \mathrm{O}_{13}$ & Betanin \\
\hline 2 & 4.55 & {$[\mathrm{M}+\mathrm{H}]^{+}$} & 551.1515 & 551.1513 & $\mathrm{C}_{24} \mathrm{H}_{26} \mathrm{~N}_{2} \mathrm{O}_{13}$ & Isobetanin \\
\hline 3 & 4.84 & {$[\mathrm{M}]^{+}$} & 637.1517 & 637.1517 & $\mathrm{C}_{27} \mathrm{H}_{29} \mathrm{~N}_{2} \mathrm{O}_{16}{ }^{+}$ & Phyllocactin \\
\hline 4 & 4.87 & {$[\mathrm{M}+\mathrm{H}]^{+}$} & 637.1510 & 637.1517 & $\mathrm{C}_{27} \mathrm{H}_{28} \mathrm{~N}_{2} \mathrm{O}_{16}$ & $\begin{array}{c}\text { Betanidin-5- } O-\left(6^{\prime}-O-3\right. \\
\text { hydroxybutyril- } \beta \text {-glucoside })\end{array}$ \\
\hline 5 & 4.97 & {$[\mathrm{M}+\mathrm{H}]^{+}$} & 637.1511 & 637.1517 & $\mathrm{C}_{27} \mathrm{H}_{28} \mathrm{~N}_{2} \mathrm{O}_{16}$ & Isophyllocactin \\
\hline 6 & 5.00 & {$[\mathrm{M}+\mathrm{H}]^{+}$} & 637.1512 & 637.1517 & $\mathrm{C}_{27} \mathrm{H}_{28} \mathrm{~N}_{2} \mathrm{O}_{16}$ & $\begin{array}{c}\text { Isobetanidin-5-O-(6'-O-3 } \\
\text { hydroxybutyril- } \beta \text {-glucoside })\end{array}$ \\
\hline 7 & 5.05 & {$[\mathrm{M}+\mathrm{H}]^{+}$} & 769.1943 & 769.1943 & $\mathrm{C}_{32} \mathrm{H}_{37} \mathrm{~N}_{2} \mathrm{O}_{20}$ & Apiosyl-malonyl-betanin \\
\hline
\end{tabular}

\subsection{Optimization of the UAE Method}

The main objective of our study was to apply an experimental design to the optimization of the influencing variables in betacyanin extractions from red dragon fruit samples. A BBD was generated for five UAE independent variables at three levels each. These variables and their values were temperature (A: $10,35,60^{\circ} \mathrm{C}$ ), solvent composition (B: 20, 50, 80\% methanol in water), sample to solvent ratio (C: 0.1:10, 0.2:10, 0.3:10 g/mL), power (D: 20, 45, $70 \%$ ), and cycle (E: $0.3,0.5,0.7 \mathrm{~s}^{-1}$ ). Given the unit and range differences between factors, 
their values were normalized to a range of -1 to +1 so that a more even response would be obtained [21]. A BBD comprising 46 experiments including three center points was completed, and a mathematical model based on the resulting data was elaborated. The total responses for the BBD (Table 2) were obtained as the relative values of the maximum peak areas (\%) of the seven identified betacyanin compounds: betanin (BET), isobetanin (IBET), phyllocactin (PHY), betanidin-5-O-(6'-O-3 hydroxybutyril- $\beta$-glucoside) (BET5O), isophyllocactin (IPHY), isobetanidin-5-O-(6'-O-3 hydroxybutyril- $\beta$-glucoside) (IBET5O), and apiosyl-malonylbetanin (AMBET). These responses were then entered into the corresponding BBD table in STATGRAPHICS Centurion XVI to conduct the analysis of variance (ANOVA).

The ANOVA determined the statistical significance of each effect by comparing their mean square against an estimate of the experimental error. The standardized data ( $p 0.05)$ in decreasing order of importance have been plotted in a Pareto chart (Figure 2). The bars crossing the vertical line correspond to the factors or combination of factors that have a significant effect on the response. In this case, three linear effects have $p$-values below 0.05 , which indicates that they present significant differences at a 95.0\% confidence level.

On the basis of the results displayed in the standardized Pareto chart (Figure 2), the significant effects and the corresponding course of action that is required to optimize the extractions can be identified. The solvent composition ( $p$ 0.0063), the sample to solvent ratio ( $p$ 0.0126) and the cycle ( $p$ 0.0302) were identified as the main influential variables with regard to the recovery of betacyanins. Both the solvent composition and the cycle exhibited inverse relations, which means that greater recoveries were achieved by decreasing the percentage of methanol in the solvent and/or reducing the cavitation cycle of the ultrasounds. In contrast, the ratio of solvent to sample had a positive effect, as recoveries grew with an increasing ratio.

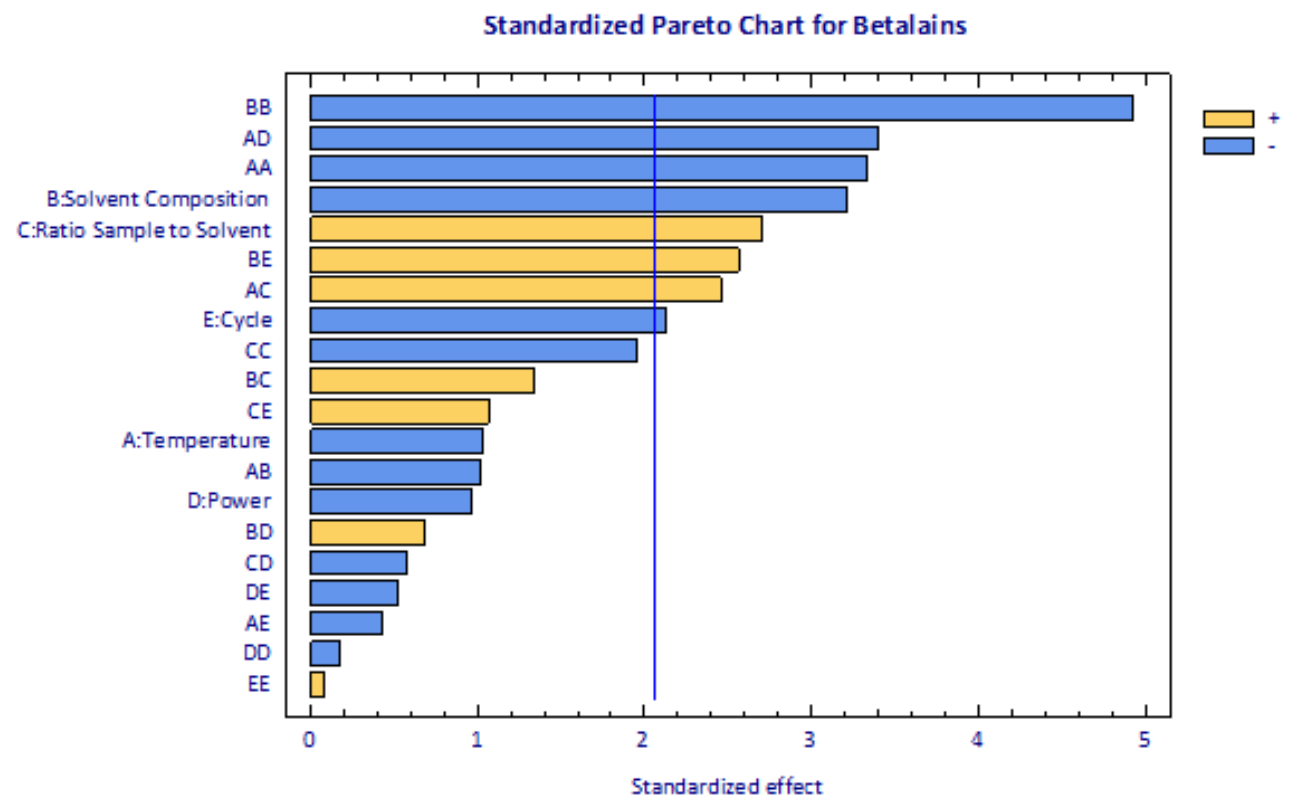

Figure 2. Pareto chart of the standardized effects from the variables in the extraction process. A: Temperature; B: Solvent composition; C: Ratio sample to solvent; D: Ultrasound power; E: Cycle.

\subsection{Prediction Capability of the Regression Model}

The RSM results were estimated based on the experimental design generated by BBD to produce a regression model for each response. The acquired mathematical model was used to establish a predictive equation for each individual betacyanin in red dragon fruit based on the significant variables. Only the significant variables $(p<0.05)$ were considered for the optimization, so that the number of factors for an optimized design 
would remain low and excessive variability would be avoided. The resulting equation for the optimization of a UAE process would be as follows:

$$
\text { Betacyanin }=88.5-5.8 B+4.9 C-3.9 E+8.9 A C-12.3 A D+9.3 B E-8.2 A A-12.1 B B
$$

where $A$ is the temperature; $B$ is the solvent composition; $C$ is the sample-to-solvent ratio; $D$ is the ultrasound power; and $E$ represents the cycle.

A lack-of-fit test was performed in order to ascertain whether the selected model successfully described the actually observed data or whether a more complex model would be required. The test was carried out by comparing the variability of the current model residuals against the variability of the results from a number of replicate extractions that used the same variable settings. Since the $p$-value for the lack-of-fit $(0.1920)$ obtained by ANOVA was greater than 0.05 , the model appears to be satisfactory for the data of interest at a $95.0 \%$ confidence level.

According to the ANOVA results, the significance of the independent variables and the adequacy of the model $(p>0.05)$ has been confirmed, whilst the $R^{2}$ statistics show how the model matches the variability of the responses. The differences between the predicted values and those calculated by the ANOVA indicated a residual standard deviation of 5.16219 while the mean absolute error was $5.57 \%$. It can therefore be concluded that the regression model can be considered reliable for the optimization of the process based on predicted responses.

\subsection{Response Optimization}

The correct determination of the significant independent variables is an essential aspect to be considered for the optimization of the extraction method in order to achieve the best possible extraction yields. Based on the predictive model, three-dimensional surface graphs were plotted to determine the influence of the likely relationships between the different independent factors on the response. The DOE results enabled the plotting of the response surfaces of the significant variables: solvent composition (B); sample-tosolvent ratio (C); and cycle (E) (Figure 3).

As can be observed, the optimum extraction yield (105\%) was established at coordinates -0.952286 for solvent composition, 0.106804 for solvent to sample ratio, and -1.0 for cycle. Based on the RSM, the optimized extraction of betacyanins from red dragon fruit samples using UAE would be achieved when applying a $54.6{ }^{\circ} \mathrm{C}$ extraction temperature, $0.3 \mathrm{~s}^{-1}$ cycle, $20 \%$ ultrasound power, $21.4 \%$ methanol in water, and a $0.2: 10 \mathrm{~g} / \mathrm{mL}$ sample to solvent ratio.

No significant differences could be noted between the yields obtained from the additional (lower cycle and ultrasound power) extractions and those obtained from the initial (optimized) extractions, even if a slightly greater amount was obtained through the latter.

It can be observed from these results that the optimal cycle and ultrasound power values both correspond to their minimums within the range considered in this study. These intervals had been determined based on the existing bibliography and on the extensive experience of our research group with this type of design. In order to verify if a greater yield of betacyanins could be obtained using both lower cycles and ultrasound power values, a number of additional extractions were conducted according to the previously determined optimal conditions with regard to solvent, temperature, sample to solvent ratio and time, while both cycle and ultrasound power would be decreased to $0.2 \mathrm{~s}^{-1}$ and $15 \%$ respectively. These additional extractions were carried out in triplicate and their results were compared to those obtained under the previously determined optimal conditions. 

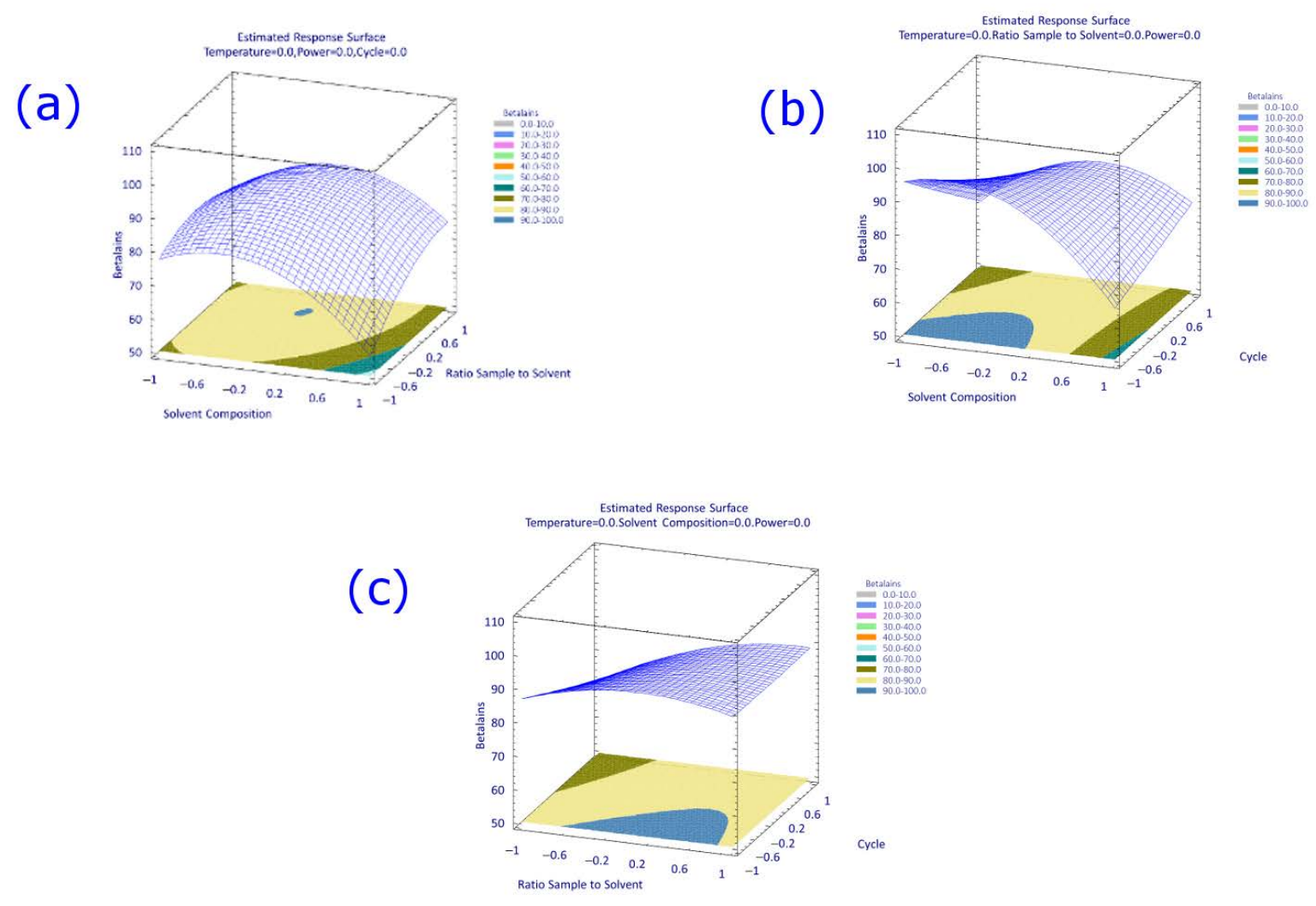

Figure 3. Response surface graphs according to the significant independent variables: (a) solvent composition (B) vs. sample-to-solvent ratio (C); (b) solvent composition (B) vs. cycle (E); (c) sample-to-solvent ratio (C) vs. cycle (E), since they are the most significant variables regarding extraction yield.

\subsection{Optimal Extraction Time}

Once the five previous variables had been optimized, the optimal extraction time was still to be determined. For this purpose, a 2 to $30 \mathrm{~min}$ range was considered. The data collected from this particular investigation are presented in Figure 4. It can be seen in the graph that the individual recoveries of betacyanin compounds by means of UAE reach a plateau at $5 \mathrm{~min}$ of extraction time and start decreasing after $20 \mathrm{~min}$. Consequently, 5 min was set up as the optimized extraction time to ensure that no compound degradation would take place during the extraction process. The extraction time reported by recent studies on the extraction of betacyanin compounds from red dragon fruit ranges between 15 and $120 \mathrm{~min}$, depending on the extraction method used. A shorter extraction time is expected when the compounds are extracted with the aid of sonication, compared to that of traditional methods [22,23]. 


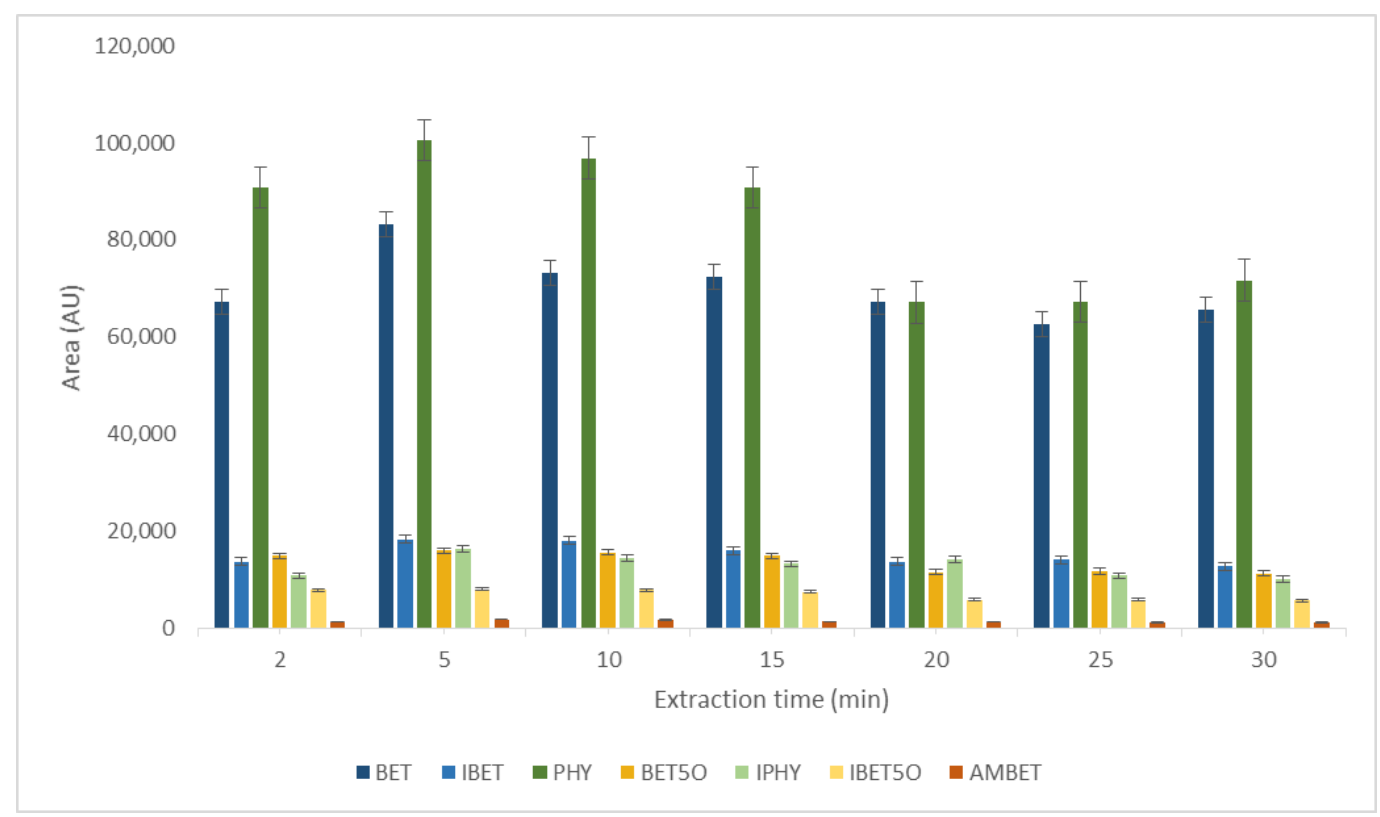

Figure 4. Effect of extraction time on the amount of betacyanins extracted.

\subsection{Validation of the UAE Method}

To check the reliability of the UAE method developed, its repeatability and intermediate precision were examined. A total of 15 extractions were performed and these were scheduled as follows: 9 extractions were performed on the first day of the study and 3 more extractions on each of the two following days. The evaluation of both repeatability and intermediate precision was carried out considering the separate values of the seven betacyanins in the samples. The repeatability results (CV) ranged from $1.04 \%$ for apiosyl-malonyl-betanin to $2.23 \%$ for betanin, with an average value of $1.56 \%$. The intermediate precision results ranged from $1.15 \%$ for apiosyl-malonyl-betanin to $5.51 \%$ for phyllocactin, with an average value of $2.94 \%$ (Table 4). This high reproducibility and intermediate precision of all of the values is consistent with the stability of the betacyanin compounds exposed to ultrasound waves at the extraction temperatures considered in our study.

Table 4. Repeatability and intermediate precision of the developed method.

\begin{tabular}{|c|c|c|c|c|c|c|c|c|}
\hline & & BET & IBET & PHY & ВET5O & IPHY & IBET5O & AMBET \\
\hline \multirow{2}{*}{ CV $(\%)$} & $\begin{array}{l}\text { Repeatability } \\
\quad(n=9)\end{array}$ & 2.23 & 1.92 & 1.45 & 1.21 & 1.48 & 1.57 & 1.04 \\
\hline & $\begin{array}{l}\text { Intermediate precision } \\
\qquad(n=3+3+3)\end{array}$ & 3.88 & 3.28 & 5.51 & 2.00 & 2.16 & 1.61 & 1.15 \\
\hline
\end{tabular}

\subsection{Application to Real Samples}

The optimized method was applied to determine the total and individual betacyanin content in real samples in order to verify the applicability of the method. The real samples were red dragon fruit from three different origins. The concentration of total betacyanins and the content levels of the different betacyanins in the samples were determined by means of the UAE method developed in this study and can be seen in Table 5. The results obtained are in the range of those obtained by other authors for fresh red pitaya, $0.5-0.6 \mathrm{mg} / \mathrm{g}$ [19] or $0.6-0.8 \mathrm{mg} / \mathrm{g}$ [24], and for freeze-dried samples, $1.0-1.6 \mathrm{mg} / \mathrm{g}$ [25].

The results confirmed that the fruit acquired from a Chipiona (Spain) producer was the one with the greatest total amount of betacyanins, while the other two samples had similar but lower levels. As for the distribution of each single betacyanin compound, it could be observed that their content levels in the Spanish sample were according to expectations, 
i.e., a high percentage of phyllocactin in relation to the rest of the betacyanins. Regarding the sample from Jakarta (Indonesia), the amount of betanin present in the sample was slightly greater than that of phyllocacthin. On the other hand, betanin was the major compound in the sample from Mexico. The antioxidant activity of the extracts has also been measured. It is observed that there is a concordance between the values of total betacyanins and total antioxidant activity. The antioxidant activity values are higher, since not only betacyanins provide this capacity in the extracts obtained; other compounds, such as phenolic compounds, also contribute to this activity.

Table 5. Betacyanin total content, antioxidant activity and percentage of each single betacyanin compound in the real samples.

\begin{tabular}{cccccccccc}
\hline Sample & $\begin{array}{c}\text { Betacyanin } \\
\text { Content (mg/g) }\end{array}$ & $\begin{array}{c}\text { Antioxidant } \\
\text { Activity } \mathbf{( m g T E} / \mathbf{g})\end{array}$ & $\begin{array}{c}\text { BET } \\
\mathbf{( \% )}\end{array}$ & $\begin{array}{c}\text { IBET } \\
\mathbf{( \% )}\end{array}$ & $\begin{array}{c}\text { PHY } \\
\mathbf{( \% )}\end{array}$ & $\begin{array}{c}\text { BET5O } \\
\mathbf{( \% )}\end{array}$ & $\begin{array}{c}\text { IPHY } \\
\mathbf{( \% )}\end{array}$ & $\begin{array}{c}\text { IBET5O } \\
\mathbf{( \% )}\end{array}$ & $\begin{array}{c}\text { AMBET } \\
\mathbf{( \% )}\end{array}$ \\
\hline Indonesian & $0.84 \pm 0.07$ & $1.73 \pm 0.21$ & 45.24 & 6.97 & 38.75 & 3.61 & 3.94 & 1.16 & 0.34 \\
Spanish & $1.31 \pm 0.14$ & $2.69 \pm 0.28$ & 20.07 & 3.83 & 60.79 & 5.49 & 7.43 & 2.29 & 0.08 \\
Mexican & $0.93 \pm 0.30$ & $2.47 \pm 0.36$ & 61.41 & 15.58 & 16.12 & 0.92 & 4.74 & 1.22 & n.d. \\
\hline
\end{tabular}

${ }^{*}$ Betacyanin content (mg betacyanins per $\mathrm{g}$ of dry matter; $\left.n=3\right) .{ }^{* *} \mathrm{DPPH}$ antioxidant activity (mg Trolox Equivalent per $\mathrm{g}$ of dry matter; $n=3)$.

\section{Conclusions}

The new ultrasound-assisted extraction method developed in this research for the extraction of betacyanins from red dragon fruit was successfully optimized by means of a Box-Behnken design in combination with response surface methodology. The optimum extraction conditions were established as $21.4 \%$ methanol in water at $54.6^{\circ} \mathrm{C}$ for $5 \mathrm{~min}$ under $20 \%$ ultrasound power and a $0.3 \mathrm{~s}^{-1}$ cycle and $0.2 / 10 \mathrm{~g} / \mathrm{mL}$ sample-to-solvent ratio. The proposed optimized method was effectively validated with adequate linearity and precisions values. Subsequently, the method was successfully applied to real red dragon fruit samples from different growing areas obtained through diverse cultivation methods. According to the results, it can be concluded that the ultrasound-assisted extraction method proposed in this study is a reliable, economical and rapid technique for obtaining greater yields of betacyanin compounds from red dragon fruit.

Author Contributions: Conceptualization, C.C., W.S. and M.P.; methodology, J.P., A.R.-R. and C.C.; software, G.F.B.; validation, G.F.B. and C.C.; formal analysis, J.P., M.F.-G. and C.C.; investigation, W.S., A.R.-R. and C.C.; resources, M.P. and G.F.B.; data curation, C.C., M.P. and G.F.B.; writing-original draft preparation, C.C.; writing-review and editing, W.S., M.F.-G. and G.F.B.; visualization, G.F.B.; supervision, M.P. and G.F.B.; project administration, G.F.B. and M.P.; funding acquisition, G.F.B. and M.P. All authors have read and agreed to the published version of the manuscript.

Funding: This work has been supported by the project "EQC2018-005135-P" (Equipment for liquid chromatography by means of mass spectrometry and ion chromatography) of the State Subprogram of Research Infrastructures and Technical Scientific Equipment.

Data Availability Statement: The data presented in this study is contained within the article.

Acknowledgments: The authors are grateful to the Instituto de Investigación Vitivinícola y Agroalimentaria (IVAGRO) for providing the necessary facilities to carry out the research. A special acknowledgement goes to Carmelo García Barroso (in memoriam) for his contribution to the scientific community in the area of phenolic compounds and oenology and his important inputs to this research.

Conflicts of Interest: The authors declare no conflict of interest.

\section{References}

1. Gengatharan, A.; Dykes, G.A.; Choo, W.S. Betalains: Natural plant pigments with potential application in functional foods. LWT 2015, 64, 645-649. [CrossRef]

2. Prasetyo, B.F.; Shabrina, H.; Juniantito, V.; Wientarsih, I. Activity of red dragon fruit (Hylocereus polyrhizus) juices on doxorubicininduced nephropathy in rats. IOP Conf. Ser. 2018, 196, 12037. [CrossRef] 
3. Mahayothee, B.; Komonsing, N.; Khuwijitjaru, P.; Nagle, M.; Müller, J. Influence of drying conditions on colour, betacyanin content and antioxidant capacities in dried red-fleshed dragon fruit (Hylocereus polyrhizus). Int. J. Food Sci. Technol. 2019, 54, 460-470. [CrossRef]

4. Martinez, R.M.; Longhi-Balbinot, D.T.; Zarpelon, A.C.; Staurengo-Ferrari, L.; Baracat, M.M.; Georgetti, S.R.; Sassonia, R.C.; Verri, W.A.; Casagrande, R. Anti-inflammatory activity of betalain-rich dye of Beta vulgaris: Effect on edema, leukocyte recruitment, superoxide anion and cytokine production. Arch. Pharm. Res. 2015, 38, 494-504. [CrossRef]

5. Pietrzkowski, Z.; Nemzer, B.; Spórna, A.; Stalica, P.; Tresher, W.; Keller, R.; Jimenez, R.; Michałowski, T.; Wybraniec, S. Influence of betalain-rich extract on reduction of discomfort associated with osteoarthritis. N. Med. 2010, 1, 12-17.

6. De Mello, F.R.; Bernardo, C.; Dias, C.O.; Gonzaga, L.; Amante, E.R.; Fett, R.; Candido, L.M.B. Antioxidant properties, quantification and stability of betalains from pitaya (Hylocereus undatus) peel. Ciência Rural 2014, 45, 323-328. [CrossRef]

7. Aliaño-González, M.J.; Ferreiro-González, M.; Espada-Bellido, E.; Carrera, C.; Palma, M.; Álvarez, J.Á.; Ayuso, J.; Barbero, G.F. Extraction of anthocyanins and total phenolic compounds from açai (Euterpe oleracea Mart.) using an experimental design methodology. Part 1: Pressurized liquid extraction. Agronomy 2020, 10, 183. [CrossRef]

8. Shang, Y.F.; Kim, S.M.; Um, B.-H. Optimisation of pressurised liquid extraction of antioxidants from black bamboo leaves. Food Chem. 2014, 154, 164-170. [CrossRef]

9. González-De-Peredo, A.V.; Vázquez-Espinosa, M.; Espada-Bellido, E.; Ferreiro-González, M.; Carrera, C.; Palma, M.; Álvarez, J.Á.; Barbero, G.F.; Ayuso, J. Optimization of analytical ultrasound-assisted methods for the extraction of total phenolic compounds and anthocyanins from sloes (Prunus spinosa L.). Agronomy 2020, 10, 966. [CrossRef]

10. Setyaningsih, W.; Saputro, I.E.; Carrera, C.A.; Palma, M. Optimisation of an ultrasound-assisted extraction method for the simultaneous determination of phenolics in rice grains. Food Chem. 2019, 288, 221-227. [CrossRef]

11. Cardoso-Ugarte, G.A.; Sosa-Morales, M.E.; Ballard, T.; Liceaga, A.; San Martín-González, M.F. Microwave-assisted extraction of betalains from red beet (Beta vulgaris). LWT 2014, 59, 276-282. [CrossRef]

12. Vázquez-Espinosa, M.; Espada-Bellido, E.; de Peredo, A.V.G.; Ferreiro-González, M.; Carrera, C.; Palma, M.; Barroso, C.G.; Barbero, G.F. Optimization of microwave-assisted extraction for the recovery of bioactive compounds from the Chilean superfruit (Aristotelia chilensis (Mol.) Stuntz). Agronomy 2018, 8, 240. [CrossRef]

13. Wang, L.; Weller, C.L. Recent advances in extraction of nutraceuticals from plants. Trends Food Sci. Technol. 2006, 17, 300-312. [CrossRef]

14. Laqui-Vilca, C.; Aguilar-Tuesta, S.; Mamani-Navarro, W.; Montaño-Bustamante, J.; Condezo-Hoyos, L. Ultrasound-assisted optimal extraction and thermal stability of betalains from colored quinoa (Chenopodium quinoa Willd) hulls. Ind. Crops Prod. 2018, 111, 606-614. [CrossRef]

15. Tutunchi, P.; Roufegarinejad, L.; Hamishehkar, H.; Alizadeh, A. Extraction of red beet extract with $\beta$-cyclodextrin-enhanced ultrasound assisted extraction: A strategy for enhancing the extraction efficacy of bioactive compounds and their stability in food models. Food Chem. 2019, 297, 124994. [CrossRef] [PubMed]

16. Koubaa, M.; Barba, F.J.; Grimi, N.; Mhemdi, H.; Koubaa, W.; Boussetta, N.; Vorobiev, E. Recovery of colorants from red prickly pear peels and pulps enhanced by pulsed electric field and ultrasound. Innov. Food Sci. Emerg. Technol. 2016, 37, 336-344. [CrossRef]

17. Setyaningsih, W.; Duros, E.; Palma, M.; Barroso, C.G. Optimization of the ultrasound-assisted extraction of melatonin from red rice (Oryza sativa) grains through a response surface methodology. Appl. Acoust. 2016, 103, 129-135. [CrossRef]

18. Martín-García, B.; Pasini, F.; Verardo, V.; Díaz-de-Cerio, E.; Tylewicz, U.; Gómez-Caravaca, A.M.; Caboni, M.F. Optimization of sonotrode ultrasonic-assisted extraction of proanthocyanidins from brewers' spent grains. Antioxidants 2019, 8, 282. [CrossRef] [PubMed]

19. Yong, Y.Y.; Dykes, G.; Lee, S.M.; Choo, W.S. Comparative study of betacyanin profile and antimicrobial activity of red pitahaya (Hylocereus polyrhizus) and red spinach (Amaranthus dubius). Plant. Foods Hum. Nutr. 2017, 72, 41-47. [CrossRef]

20. Lima, A.C.V.D.; Dionisio, A.P.; Abreu, F.A.P.D.; Silva, G.S.D.; Lima, R.D., Jr.; Magalhães, H.C.R.; Garruti, D.D.S.; Araújo, I.M.D.S.; Artur, A.G.; Taniguchi, C.A.K.; et al. Microfiltered red-purple pitaya colorant: UPLC-ESI-QTOF-MSE-based metabolic profile and its potential application as a natural food ingredient. Food Chem. 2020, 330, 127222. [CrossRef]

21. Baş, D.; Boyac1, İ.H. Modeling and optimization I: Usability of response surface methodology. J. Food Eng. 2007, 78, 836-845. [CrossRef]

22. Ramli, N.S.; Ismail, P.; Rahmat, A. Influence of conventional and ultrasonic-assisted extraction on phenolic contents, betacyanin contents, and antioxidant capacity of red dragon fruit (Hylocereus polyrhizus). Sci. World J. 2014, 2014, 964731. [CrossRef] [PubMed]

23. Tang, C.S.; Norziah, M.H. Stability of betacyanin pigments from red purple pitaya fruit (Hylocereus polyrhizus): Influence of pH, temperature, metal ions and ascorbic acid. Indones. J. Chem. 2007, 7, 327-331. [CrossRef]

24. Tenore, G.C.; Novellino, E.; Basile, A. Nutraceutical potential and antioxidant benefits of red pitaya (Hylocereus polyrhizus) extracts. J. Funct. Foods 2012, 4, 129-136. [CrossRef]

25. Raj, G.V.S.B.; Dash, K.K. Ultrasound-assisted extraction of phytocompounds from dragon fruit peel: Optimization, kinetics and thermodynamic studies. Ultrason. Sonochem. 2020, 68, 105189. [CrossRef] 